\title{
REVÁlida PARA LA PROFESIÓN DE tRABajo SOCIAL EN PUERTO RICO: ASPECTOS A REFLEXIONAR
}

\author{
Pablo D. Ramos Cruz ${ }^{1}$
}

\section{Resumen}

Por los últimos años, la profesión del Trabajo Social en Puerto Rico ha estado en un fuerte debate de si se debería crear una reválida para la misma. Lo interesante es que, en general, nuestro gremio profesional no simpatiza con la filosofía detrás de las reválidas. Aun así, presiones externas a la profesión han convencido a una parte del gremio sobre la necesidad de implementar una reválida, aunque vaya en contra de sus ideales. Entre dichas presiones se encuentran, por mencionar algunas: 1) Que seamos de las pocas profesiones que no revalidan; 2) Que existe la posibilidad que el Estado imponga una reválida sin nuestra consulta; 3) Que se considera que la profesión amerita tener una reválida para ganar prestigio; 4) Que urge la necesidad de establecer un filtro de los y las egresadas de las universidades para reducir las querellas éticas en el futuro y de vez regular la formación profesional.

Dicho esto, el artículo reflexionará mis preocupaciones de implementarse una reválida en nuestra profesión. Entre ellas, se encuentra que podríamos terminar mercantilizando la profesión. También expongo mis inquietudes de que se establezca una reválida estilo "talla única", que tenga la intención de fracasar a los estudiantes, que homogenice los currículos, elimine el pensamiento crítico, que no sea cónsona con las inteligencias múltiples, que propicie la competencia y que sea incapaz de medir otras capacidades humanas más afines con los valores y principios de la profesión. [Palabras clave: educación en Trabajo Social, reválida, currículos, pensamiento crítico, enseñar para el examen, competencias, ética].

\begin{abstract}
During the past years, the profession of Social Work in Puerto Rico, has been strongly debating on whether we should create a revalidation exam for the profession. The interesting thing is that in general, our professional colleagues are not sympathetic with the philosophy behind the revalidation exam. At the same time there are external pressures to the profession that have convinced some of the colleagues of the need to implement a revalidation exam, even if it goes against their ideals. These pressures include, to name a few: 1) we are of the few professions that do not have it; (2) there is a possibility that the State imposes us a revalidation exam without consultation; (3) it is considered that the profession deserves to have a revalidation exam to gain prestige; (4) that urge the need to set a filter for the graduates of the universities to reduce the ethical complaints in the future.

That said, during the article I will reflect my concerns of the implement of a revalidation exam in our profession. Among the concerns is that we could finish commodifying the profession. I also discuss my concerns for the establishment of a revalidation exam style "one-size-fits-all", which intends to fail students, to homogenize the curricula, eliminate the critical thinking, which is not consonant with the multiple intelligences, which conducive to competition and it is unable to measure other human abilities more related with the values and principles of the profession.[Keywords: education in Social Work, revalidation exam, curricula, critical thinking, teach to test, competency, ethics].
\end{abstract}

\section{Introducción}

Desde que comencé mis estudios en Trabajo Social, hace 14 años, ha estado resonando fuertemente el debate de si se debería crear una reválida para la profesión del Trabajo Social en Puerto

\footnotetext{
${ }^{1}$ Maestro en Trabajo Social. Supervisor de trabajo social en Casa Nuestra Gente, Municipio de San Juan. Profesor conferenciante en la Universidad Interamericana-Aguadilla.
} 
Rico. Lo interesante es que, en general, nuestro gremio profesional no simpatiza con la filosofía detrás de las reválidas. Esto porque se considera incompatible con el Trabajo Social crítico y propositivo al que aspiramos a desarrollar en el país.

Ahora bien, el Colegio de Profesionales del Trabajo Social de Puerto Rico (CPTSPR) desde la presidencia de Gloria Rivera-Centeno y en el presente, con Larry Alicea-Rodríguez, ha estado alineado y trabajando hacia esta meta. Este nuevo Trabajo Social que buscamos alcanzar como colectivo, ha sido traído varias veces por la colega Raquel Seda-Rodríguez. Un ejemplo de esto, fue su artículo titulado Legado de Carmen Rivera de Alvarado a la profesión de Trabajo Social en Puerto Rico, en el cual la autora visualiza hacia donde se debe dirigir la profesión. Seda (2012), propone una profesión no neutral, actuando de acuerdo con nuestros principios éticos y un gran compromiso con la equidad y la justicia social. Añade que, como trabajadores sociales debemos aspirar a la conciencia social crítica. Y como gremio, reflexionar y problematizar la realidad para así, en la práctica, integrarnos al proceso de acción sociocultural en búsqueda de la transformación personal, colectiva y macroestructural.

A pesar de este lineamiento, coexiste en la profesión presiones externas que han convencido a una parte del gremio profesional de la necesidad de implementar una reválida. Entre dichas presiones se encuentran, por mencionar algunas: 1) Que seamos de las pocas profesiones que no revalidan; 2) Que existe la posibilidad que el Estado nos imponga una reválida sin nuestra consulta; 3) Que se considera que la profesión amerita tener una reválida para de esta manera ganar prestigio; 4) Que urge la necesidad de establecer un filtro de los y las egresadas de las universidades para de esta manera reducir las querellas éticas en el futuro y de vez regular la formación profesional.

La discusión se puede simplificar a si es necesario o no, establecer una reválida al final de los estudios universitarios que funja como puerta de acceso al ejercicio de la profesión. Es por esto, que he sentido la necesidad de reflexionar sobre las repercusiones que pudiera tener la implementación de una reválida en la profesión del Trabajo Social. La imposición de una reválida a la profesión no es un asunto liviano el que se deba aprobar por las razones antes esbozadas. Este es un asunto que puede tener el efecto de limitar la entrada y el ejercicio de la profesión a diversos colegas, brindándoles la oportunidad a solo algunos de obtener el título de trabajador o trabajadora Social.

Además, siempre que se discute al interior de la profesión la necesidad de enmendar la ley que regula el ejercicio del Trabajo Social en Puerto Rico, sale a relucir el tema de la reválida. Como exmiembro, expresidente y ahora coordinador de la Comisión Permanente para Estudiantes del Colegio de Profesionales del Trabajo Social en Puerto Rico, me motiva a estar vigilante para que los procesos de toma de decisiones del gremio sean beneficiosas tanto para los y las actuales estudiantes de Trabajo Social, así como para el bienestar de las futuras generaciones de estudiantes y aspirantes a la práctica del Trabajo Social.

Linn (2001), nos explica que los debates sobre las reválidas, existen desde que se crearon los exámenes estandarizados. Han coexistido por dos siglos, tanto la demanda por más y mejores exámenes, con la oposición y las fuertes críticas a dicho tipo de evaluación. Históricamente el péndulo de la política educativa se ha movilizado desde el lado del apoyo incondicional a las pruebas estandarizadas hasta el lado del fuerte repudio a ellas y nuevamente hacia la otra dirección. El autor, para demostrar lo antiguo del debate, encontró un estudio en el cual se mencionan las controversias relacionadas a lo que se entiende fue la primera prueba estandarizada en el año 1840. La misma, intentaba hacer una comparación en el desempeño de diferentes niños en una prueba de ortografía.

Por tanto, el debate de la reválida de Trabajo Social continuará independientemente de si se decide implementar o no en la profesión. Para ver un ejemplo de esto, en la actualidad basta con leer el rotativo El País que es de gran difusión en España, en donde se explica cómo en 1970 el Estado derogó la reválida en el sistema educativo del país y ahora el gobierno de turno quiere volver a traer la reválida a pesar de no tener el apoyo de las principales instituciones y organizaciones educativas. Esto, demuestra la complejidad del asunto y la importancia de que el gremio se posicione con respecto a una reválida en nuestra profesión luego de amplios debates para así poder estar claros qué estamos defendiendo y por qué.

Dicho lo anterior, mi intención en este escrito es hacer una llamado de alerta a que el asunto de la reválida no resolverá las problemáticas que enfrentamos actualmente, tanto a nivel de la educación del Trabajo Social como en la práctica de la profesión. Revalidar no mejorará la enseñanza, pero si añadirá 
dificultad para obtener una licencia. Los estudiantes al graduarse, han pasado por cursos teóricos, prácticas supervisadas, exámenes comprensivos, exámenes de grado, investigaciones, tesis, entre otros métodos de evaluación cualitativos y cuantitativos (visitas de campo, role plays, observación de intervenciones profesionales, redacción de propuestas de investigación, exámenes en el salón de clase, exámenes en el hogar, presentaciones orales y escritas, etc.) con el fin de asegurar su conocimiento y dominio de las destrezas requeridas para ejercer adecuadamente la profesión de Trabajo Social. Todos sabemos que la educación del Trabajo Social en Puerto Rico necesita una transformación, pero existen otras maneras más cónsonas con lo que sería un proyecto educativo de país que no implican una doble o triple revisión de lo que se alega que el o la estudiante debe haber aprendido.

Lo más preocupante de implementar una reválida ahora, es el contexto económico, político y social en que se encuentra el país. Estamos en un momento de crisis económica y precariedad laboral tanto para el profesional de trabajo social como para todos los puertorriqueños y puertorriqueñas, por tanto incluir este nuevo requisito implicaría la imposición de una carga económica adicional al futuro profesional antes de que se garantice y legisle para que exista justicia laboral para todas y todos los trabajadores sociales.

También sería oneroso añadirle un rol adicional al Estado, representado por las Juntas Examinadoras, bajo la actual crisis fiscal en que nos encontramos. Hemos sido testigo como el Estado poco a poco se ha desmantelado y ha relegado muchas de sus responsabilidades al sector privado. En el actual contexto neoliberal, no pasará mucho tiempo en que el Estado les quitará la responsabilidad de las reválidas a las Juntas Examinadoras y se la delegará a una agencia privada con las implicaciones nefastas que eso traería a nuestra profesión. Además, con la crisis fiscal actual no se asegura que las Juntas Examinadoras continúen siendo responsables de administrar las reválidas, por tanto no se podría garantizar que habrá cierta estabilidad en el nuevo sistema que se desea implementar.

En un estudio realizado por Gely (2007), sobre las reválidas en Puerto Rico, se encontró serias dificultades en el manejo de los exámenes de reválida y en el funcionamiento de las Juntas Examinadoras que las administraban. Algunos de los hallazgos fueron los siguientes: 1) Inconsistencias en la recopilación y divulgación de los datos entre las Juntas Examinadoras; 2) No contaban con un organismo que evalúe y audite el proceso; 3) Reducción sistemática de las tasas de aprobación de reválidas de diversas profesiones; 4) Aumento en la cantidad de examinados de diferentes disciplinas y por otro lado, una reducción sistemática en las tasas de aprobación; y 5) Cuestionamientos y preocupaciones en torno a la validez y confiabilidad de los exámenes en las diferentes disciplinas.

Lo que sí es sorprendente, y es una pena que nos hagamos de la vista larga, es que todos los años en los principales rotativos del país, salen a relucir las diferentes problemáticas que traen las reválidas para la profesión de la abogacía, la medicina, la psicología, entre otras. Todos los años publican artículos cuestionando la existencia de las reválidas y las limitaciones que estas tienen. Por ejemplo, es de conocimiento público los señalamientos que han traído los mecánicos de que la reválida solamente la aprueba el $25 \%$ de los aspirantes. En Consejería, han salido reportajes de los aspirantes reclamando que, para aprobar la reválida tienen que obtener una puntuación de $90 \%$ o más. Con respecto a los médicos, ha habido hasta demandas legales porque han observado que la reválida solamente la aprueban los estudiantes de una sola universidad. Y en el presente, el caso más sonado en la prensa local ha sido el de los psicólogos, donde nadie ha aprobado la reválida por los últimos dos años.

El denominador común entre las diferentes quejas ha sido que las reválidas no recogen toda la diversidad de saberes que existen en las profesiones o como mínimo, los saberes que ofrecen las diferentes universidades. Por tanto, el fracaso en una reválida no implica que el estudiante no tenga los conocimientos mínimos necesarios para ejercer la profesión, si no que el día que tomó el examen no seleccionó las respuestas que el comité de reválida consideró correctas.

Popham (1999), nos explica que es probable que los y las estudiantes dominen una enorme cantidad de conocimientos y/o destrezas, pero que no será posible demostrarlo en un examen estandarizado. El autor aclara que esto sucede porque la principal limitación que tienen las pruebas estandarizadas es su tamaño. Porque si una prueba cubriera todos los conocimientos y las destrezas de una profesión, sería excesivamente larga y no sería costo-efectiva.

Ignacio Barrenechea (2010), sostiene que las evaluaciones estandarizadas deben caer, por lo general, en la metodología de selección múltiple por una cuestión de economía, ya que cuanto más 
tiempo lleve corregir el examen más costoso será el sistema. El autor entiende que con ello hace que los métodos de evaluación sobre los cuales reposan estos exámenes sean defectuosos, ya que no son capaces de medir todas las habilidades aprendidas, dado que no todas las habilidades son cuantificables con tanta facilidad.

Popham (1999), amplía que, debido a la sustancial diversidad curricular que pudiera existir, el comité que realizará la prueba estandarizada se verá obligado a crear un examen que se asemeje al concepto de "talla única" (que le sirve a todo el mundo). Dicho comité diseñador hará el intento de seleccionar las premisas, preguntas o temas que puedan medir los principales conocimientos y destrezas de la profesión. Pero, el autor dice que al final de cuentas no logran conseguirlo realmente y lo que sucede es que siempre dejaran fuera conocimientos y destrezas que son importantes y pertinentes para ciertos contextos determinados.

Lo peligroso de todo esto, es que indirectamente con este tipo de pruebas se hace una imposición de referentes teóricos sobre otros sin haber sido necesariamente decidido entre el gremio profesional. Si utilizamos, por ejemplo, lo que pudiera ser la reválida graduada, el comité tendría que realizar un examen dirigido hacia los estudiantes de concentración de Trabajo Social Clínico porque son la mayoría (cinco programas graduados) sin que se afecten los estudiantes de la concentración de Trabajo Social Forense (que solo tiene un programa). Ese panorama es solamente entre dos concentraciones. Imaginémonos cómo tendría que ser dicha reválida si añadimos el Trabajo Social en la Administración, el Trabajo Social en el Servicio Directo, Trabajo Social con Familias, Trabajo Social con Comunidades y el Trabajo Social con Políticas Sociales, entre otras concentraciones que pudieran surgir en el futuro. En otras palabras, quiéranlo o no, recaerá sobre unos pocos (comité de reválida) la decisión de quienes pasan por la puerta de entrada a la profesión.

Pérez (2013), menciona que las reválidas responden al primer modelo pedagógico uniforme ("talla única"). Según el autor, esto significa que el modelo de talla única, uniforme, es un modelo fijado en el pasado, obsoleto, propio de la ideología y de la metodología de las cadenas de montaje de la era industrial, basada en la división estricta del trabajo mecanizado y en la jerarquía de las relaciones laborales y sociales. Añade el autor, que esto contrasta con lo que la mayoría de las investigaciones indica, en donde se confirma que el aprendizaje es un proceso permanente, apoyado en aprendizajes previos, no un producto acabado que el o la estudiante demostrará en un examen final.

Gómez (2004), nos explica que este tipo de pruebas estandarizadas están dominadas por el enfoque positivista. Este autor critica que bajo este concepto de medición del desempeño subyace la noción de adquisición continua de conocimiento, que va desde la carencia total de competencias, hasta el desempeño perfecto. Para el autor entonces, esto implicaría que se entienda que el nivel de rendimiento de un individuo se ubica en algún punto de este continuum, según lo indicado por los comportamientos que exhiba durante ese día en el examen.

¿Esto no les parece contradictorio con nuestra mirada holística del ser humano? ¿No les parece contradictorio que nos caractericemos por ser críticos al posicionarnos en contra de establecer diagnósticos a través de escalas o pruebas estandarizadas, pero a la misma vez avalemos que se categoricen a los estudiantes con una reválida?

Ante dichos cuestionamientos, Pérez (2013), nos propone una manera diferente de ver el aprendizaje. Para el autor, los aprendizajes requeridos en la era digital son aquellos que han sido considerados como de orden superior (creatividad y pensamiento crítico) y no los meramente reproductivos (memoria y repetición). Además, para Pérez (2013) los y las aprendices son diferentes desde el punto de vista cultural, genético, social, emocional e intelectual. Estos y estas desarrollan recursos personales singulares de aprendizaje y diferentes unos de otros, entre los cuales se encuentran, modos de percibir, organizar, reaccionar y evaluar. Precisamente, la riqueza del individuo y de la sociedad reside en el respeto y fomento de la diversidad creativa de todos y cada uno de sus miembros.

Otra problemática que nos trae Popham (1999), es que los exámenes estandarizados están creados para fracasar al estudiantado. Según él, estas pruebas tienen la intención de buscar que la mayoría de las y los estudiantes reprueben. Nos explica que en una prueba estandarizada los ítems que son respondidos correctamente por el 40 al 60 por ciento de los estudiantes hacen un buen trabajo en dispersar los puntajes totales de los examinados. En cambio, los ítems que son respondidos correctamente por un gran número de estudiantes, no contribuyen a dispersar convenientemente los puntajes de las 
pruebas, por tanto esos ítems suelen no pasar el corte final cuando una prueba estandarizada de logros se diseña por primera vez o serán desechados cuando se revise la prueba.

Basado en estas observaciones, se puede concluir que en el caso de que se implemente una reválida en Trabajo Social la intención de garantizar que el estudiantado demuestre dominio de los conocimientos mínimos pasará a un segundo plano. Porque en el proceso de construcción de pruebas, tan pronto como los expertos que evalúan dichos exámenes cataloguen una premisa como fácil, la eliminarán, por el hecho de que casi todos los y las estudiantes la han contestado correctamente. Por este dato, es que podemos observar que en otras profesiones, el porciento de pasantía de muchos exámenes de reválida fluctúa en el $40 \%$ al $60 \%$. ¿Sería un filtro efectivo la reválida que permita pasar a estudiantes que tienen problemas con los alegados fundamentos básicos de la profesión, pero dichos fundamentos no serán considerados en la reválida por entenderse que son muy genéricos?

Si nos fijamos en esos porcientos, la norma general revela que la reválida es aprobada por la mitad o menos de los y las aspirantes que la toman, podemos razonablemente concluir que la reválida es un instrumento de selección a la profesión y no para mejorar la educación. La verdadera razón que hay detrás de ella no es una desinteresada apuesta por la calidad de la educación, sino el deseo de reducir la oferta para determinados puestos, limitándola a aquellos que obtengan el título cuando aprueben el examen. Al final de cuentas, el fracaso de los estudiantes es beneficioso para el mercado, ya que los y las estudiantes tendrán que pagar de nuevo por el examen si desean repetirlo. El hecho de que en la mayoría de las profesiones no hay un límite de veces para tomar la reválida, confirma que el mercado no tiene interés en servir de supuesto filtro, sino que su mayor interés es aumentar el número de personas que pagan por tomar el examen. Por esto, podemos concluir que la reválida es un instrumento de limitación o restricción a la entrada a la profesión que realmente no mide que las personas cumplan con unos conocimientos mínimos para entrar a ejercer una profesión.

Valle (2001), critica las reválidas por esto mismo de que son un proceso selectivo a fin de cuentas. Según el autor, el problema con la reválida es que es un examen no para un proceso de ingreso a estudiar la profesión, sino para la obtención del título. Según lo que plantea el autor, esto podría dar lugar, a una profesión elitista y a la misma vez profundizar la desprofesionalización del Trabajo Social.

El elitismo se daría entre los profesionales con licencia por haber pasado una reválida y los profesionales que no tienen licencia a pesar de cumplir con toda la preparación académica. La desprofesionalización se profundizará cuando el mercado comience a emplear a los individuos que estudiaron Trabajo Social, pero no aprobaron la reválida, para de esta manera poder pagarles menos "justificadamente". Esto sucede ahora mismo con los que estudiaron abogacía, en donde en un sinnúmero de empresas seleccionan individuos que no hayan tomado o aprobado la reválida de derecho para así pagarles menos por sus servicios.

En la actualidad, ya los patronos les están asignando puestos de coordinador de servicios, manejador de casos, entre otros puestos a colegas que cumplen con todos los requisitos de ley. Imaginémonos qué sucederá cuando nosotros mismos les demos una excusa legal a estos patronos para darles rienda suelta al mercado a que les pague a los colegas lo que ellos entiendan. Al final de cuentas, no son trabajadores y trabajadoras sociales porque aunque se graduaron y tienen la preparación, no tendrán la licencia porque no pasaron la reválida. En teoría, en el futuro se podría tener un sinnúmero de individuos que estudiaron Trabajo Social, haciendo Trabajo Social, pero con un solo supervisor que haya pasado la reválida que cofirme los documentos. A lo que es meritorio aclarar, que el asunto de la reválida no solamente afecta a los futuros aspirantes de la profesión sino, que afectaría a los que ya están en la profesión, empeorando las condiciones laborales y en dirección contraria a nuestro proyecto profesional.

Todos los esfuerzos realizados por el CPTSPR, desde el 2008, en fortalecer y concretizar un proyecto profesional del Trabajo Social se verían boicoteados con la implementación de una reválida. Dicho proyecto busca hacernos más fuertes como colectivo y a prepararnos para los retos que enfrentamos como profesión y como país. Según mencionan López y Barreto (2011) la construcción de este proyecto tiene tres asuntos medulares a saber: 1) el mejoramiento de las condiciones laborales de los trabajadores y las trabajadoras sociales; 2) la defensa de los derechos humanos; y 3) la creación de políticas sociales dirigidas a la justicia social y la equidad. $Y$ aceptar que se nos imponga una reválida seria retroceder los avances que hemos tenido como profesión por los últimos 7 años. 
A pesar de estos múltiples esfuerzos colectivos, todavía se puede escuchar en la profesión colegas que se plantean de manera consistente que se imponga una reválida a modo de "filtro" para que ejerzan la profesión los y las mejores profesionales. Sin embargo, esta reválida mantendría el statu quo si no se establecen mecanismos en las universidades que busquen mejorar la educación del Trabajo Social. Son los programas y las escuelas de Trabajo Social las que deben contar con criterios y requisitos de admisión más sólidos y rigurosos y a la vez con mecanismo de evaluación cónsonos con la misión y visión de la profesión que acompañen al estudiante durante todos sus estudios ya sea a nivel de bachillerato, de maestría o doctorado.

Cuando hablo de requisitos y criterios más sólidos y rigurosos no me refiero a aumentar el grado de dificultad para que el estudiante sea admitido al programa. Sino más bien que sean mecanismos que faciliten la identificación de ese estudiantado que es cónsono con los valores y principios de la profesión. Además, una vez entran a la universidad, es importante evaluar que el desempeño, la actitud y aptitud de los y las estudiantes vayan a la par con el ejercicio de una profesión basada en los derechos humanos y la ética.

La ética siempre sale a relucir cuando se discute el tema de la reválida. Por tanto, existe una línea fina en cuestión de hasta dónde las Juntas Examinadoras pueden tomar decisiones sin caer en convertirse en una agencia de regulación y acreditación de los programas académicos, que es el problema que traen las reválidas. Se entiende el interés de las Juntas Examinadoras para atajar los dilemas éticos que suceden en la profesión. Sin embargo habría que analizar si el malpractice y los actos antiéticos disminuirán a largo plazo por el simple hecho de que ahora hay que pasar una reválida para ejercer.

En cambio, si las Juntas Examinadoras tuvieran mejores herramientas para sancionar o revocar licencias a los y las colegas que cometen actos de irresponsabilidad o por faltar a los deberes éticos de la profesión, entonces, podríamos ver diferencia en la práctica de la profesión. De esta manera, se podría atajar el sentido de impunidad que impera en nuestra profesión. En respuesta a una propuesta de reválida realizada en el 2012 por la pasada Junta Examinadora, el actual presidente del CPTSPR Larry Alicea, en oposición a los Proyectos de Ley de la Cámara 4002 y Proyecto de Ley del Senado 2627 expresó en las vistas públicas que:

Partir de la premisa que tener licencias y tomar reválidas garantiza la calidad profesional es desconocer la realidad que se vive en las profesiones con licencias especializadas o con reválidas, observen al Tribunal Examinador de Médicos, la Oficina del Procurador del Paciente, los casos del Tribunal Supremo sobre conducta ética de los abogados y hagan el análisis crítico de la relación licencia- reválida-calidad y verán que no existe correlación (2012, p. 2).

Además de los aspirantes a la profesión, entiendo que otro gran perdedor de implementarse una reválida es la educación del Trabajo Social en Puerto Rico. Según Linn (2001), esta situación hay que verla como un problema estructural relacionado con la comercialización de la educación, el cual tiene a la educación enraizada en la lógica del mercado. El autor nos explica, que se ha implementado el modelo de los negocios en la educación. Esto trajo consigo la idea de buscar la eficiencia de la educación mediante metas medibles y con estándares de control de calidad, y se ha considerado los exámenes como el instrumento para lograr dichos objetivos.

Por tanto, si ya la educación se está viendo como un negocio, es obvio que sectores que se beneficiarán económicamente querrán imponer una reválida como parte de una lógica de mercado capitalista. Esto repercute en nuevas formas de lucro para ciertos sectores ya que además de los costos de los exámenes de reválidas, se añade lo que tendría que sufragar el individuo en repasos, cursos adicionales y materiales de estudio. Entonces, el supuesto filtro se convierte en una falacia, porque todos y todas las estudiantes tendrán la oportunidad de poder repetir el examen cuantas veces puedan pagarlo o hasta que su fuerza de voluntad así lo permita. Y aceptar estas condiciones implicaría mercantilizar la profesión del Trabajo Social.

La queja más frecuente de profesores y profesoras de escuelas o programas de Trabajo Social es que se les dificulta reprobar a un estudiante que no cumple con las competencias y destrezas mínimas para desempeñarse como profesional del trabajo social. Y esa situación no se atiende con una reválida. El querer establecer una prueba estandarizada como requisito para obtener una licencia es mantener el statu quo y no trabajar con la raíz del problema que consiste en que la prohibición de fracasar a 
dichos estudiantes proviene de las mismas instituciones académicas. Es de conocimiento popular que ha sucedido que se le prohíbe a un profesor fracasar a un o una estudiante, porque no le conviene a la empresa educativa perder la aportación económica que el o la estudiante hace a la institución.

Otras de las motivaciones ocultas de las reválidas son la desconfianza en el estudiantado y que se le coloca toda la responsabilidad del fracaso a las instituciones educativas. Valle (2001), menciona que una reválida supone desconfiar del propio sistema educativo, sobre todo de sus aspectos más directamente referidos a la evaluación. Un examen de reválida es visto como un mecanismo de control externo que tiene por objetivo verificar qué profesores y centros están cumpliendo la misión que les tiene encomendada el sistema, y eso es lo que se pone en duda.

Otro efecto directo de la reválida es que se comience a evaluar a los profesores por el desempeño de sus estudiantes en dichos exámenes. Popham (1999), nos indica que al establecerse las reválidas los educadores tendrán mucha presión para demostrar su eficacia. El autor entiende que desafortunadamente, el principal indicador con el cual se evaluará el éxito del cuerpo docente de una escuela o programa, es por el desempeño de los estudiantes en la reválida. Si las puntuaciones que obtiene una escuela en pruebas estandarizadas son altas, la gente piensa que sus profesores son eficaces. Si las puntaciones en las pruebas estandarizadas son bajas, se considera que los profesores son ineficaces. El autor establece que en ambos casos, esas evaluaciones pueden ser erradas, porque la calidad educativa se mide con una vara equivocada.

Inevitablemente, tan pronto se hagan públicos los resultados de las reválidas se establecerán rankings (estilo Standard and Poor's) que fomentarán la competencia entre universidades para atraer a los alumnos. Esto podría provocar el cierre de algunos programas clasificados de chatarra. ¿Es esa nuestra meta? ¿Es eso lo que buscamos entre los programas de Trabajo Social, fomentar la competencia entre sus alumnos y con otras universidades? ¿O nuestra meta debe ser la solidaridad y la colaboración entre programas para mejorar la educación del Trabajo Social de Puerto Rico, siempre que sea respetando y celebrando la diversidad y la singularidad de cada programa?

Barrenechea (2010), expone que este tipo de examen incentiva el hacer trampa con los resultados. Entiende el autor que dado la importancia y la publicidad que se le dará a este tipo de evaluación generará mayores incentivos para mejorar los resultados, cueste lo que cueste. A través de la publicación de los resultados se confeccionarán rankings que van modificándose según la solicitud, por dar un ejemplo: 1) La universidad en la que más estudiantes aprobaron la reválida (75 estudiantes una, 48 estudiantes otra y 36 estudiantes una tercera); 2) La universidad con el mayor porciento de estudiantes que pasaron la reválida (ejemplo $83 \%$ una escuela, $65 \%$ otra, 25\% una tercera); u 3) Organizar los resultados por concentraciones (que concentraciones salieron más altas que las demás). Además de esto, el hecho de que una reválida decidirá si podrás ejercer la profesión, sin importar el excelente desempeño académico, aumentará seriamente los incentivos para corromper los resultados. Constantemente salen a relucir en la prensa historias de estudiantes que han hecho trampa por la gran frustración que sienten por no haber aprobado la reválida luego de tantos años de sacrificios en tiempo y dinero.

Otro aspecto que se verá afectado en la educación del Trabajo Social serán los currículos académicos. Los programas académicos además de tener que defender su autonomía frente al Council of Social Work Education, tendrán también el embate de medidas que están cuestionando la legitimidad y rigurosidad de los programas formativos en Trabajo Social. Pérez (2013), explica que dicha situación traerá una misión casi imposible, que es imponer un currículo homogéneo para uniformizar el desarrollo de los estudiantes con miras a que pasen una reválida en una era global, cambiante y diversificada.

Barrenechea (2010), expone que si bien es cierto que puede haber un núcleo que se repite en todos los currículos (especialmente en bachillerato), también es cierto que los estudiantes de diversos programas desarrollan y aprenden diferentes conocimientos, valores y aptitudes. El autor entiende que por razones obvias, las evaluaciones estandarizadas no contemplan estas diferencias, con lo cual, es evidente que lo que se evalúa, en la mayoría de los casos, no es necesariamente lo que los alumnos realmente saben.

El mismo autor nos trae lo que él entiende son los riesgos de "enseñar para el examen". Este concepto de Teach To The Test surge luego que estudiosos del tema observaron que en los programas educativos, como consecuencia de la presión de cumplir con los estándares propuestos, los profesores comenzaron a sacrificar actividades que fomenten la creatividad y el pensamiento crítico. Esto, con 
el fin de dedicar el mayor tiempo posible en estrategias destinadas a mejorar el rendimiento de los alumnos en los exámenes estandarizados. Por ejemplo, el autor relata que a raíz de la implementación de las evaluaciones estandarizadas los alumnos ya no aprenden a escribir bien, sino que se les instruye en cómo escribir un ensayo de cinco párrafos, formados cada uno de ellos por cinco oraciones, que les permite a los alumnos obtener una buena calificación en el examen estandarizado al cual serán sometidos. El autor encontró que algunas de las estrategias utilizadas, para mejorar los resultados de las evaluaciones son: enseñar estrategias útiles para resolver las preguntas de ese tipo de exámenes, presentar modelos de exámenes similares, basar el currículo y el proceso de aprendizaje en ellos, y/o utilizar libros de textos que contengan ejercicios similares a los de los exámenes.

Un ejemplo de lo antes expuesto se puede ver en los Estados Unidos y Puerto Rico con el programa No Child Left Behind Act. En donde dicha política educativa ha reducido los currículos a las materias que son más fácilmente evaluables a través de preguntas objetivas, excluyendo así las artes y la cultura de los currículos. Todo esto se aleja del objetivo máximo que pudieran tener los salones de clases; que es formar personas con la capacidad de reflexionar o profundizar contenidos y asociarlos a sus propios proyectos y situaciones de vida. Este programa ha sido fuertemente criticado porque sus exámenes estandarizados se enfatizan solo en la memoria y la retención de contenidos, sin atender los contextos y sin considerar otras destrezas y habilidades que los y las estudiantes tienen y que no están incorporadas en esas mediciones.

Nos traería graves problemas para el Trabajo Social si intentáramos repetir esto en nuestra profesión. En las disciplinas cuyo conocimiento es creado, que el pasar de los años cambia muy poco la teoría, que el conocimiento es estático, que los libros de textos prácticamente no cambian a pesar de los años, entonces podría considerarse tomar una reválida. Tal vez un electricista deba revalidar porque la electricidad no cambia, tal vez un mecánico deba revalidar porque los carros funcionan prácticamente igual y tal vez, una enfermera deba revalidar porque la anatomía del cuerpo humano no ha cambiado. Pero cuando se trabaja con lo social, cuando una profesión tiene como cuestión social los derechos humanos, los problemas sociales, la justicia social y la equidad, se dificulta la posibilidad de querer medir un conocimiento que vaya a la par con una sociedad cambiante.

Con respecto al concepto de inteligencia, Barrenechea (2010) nos explica que estudiosos del tema han establecido que la misma implica la habilidad de resolver problemas, de hacer contribuciones a la comunidad y de identificar nuevos desafíos por perseguir. Dichos autores sostienen que la inteligencia es un proceso dinámico y no la limitan a un valor estático y cuantificable. Este tipo de aprendizaje implica una construcción activa del conocimiento a través del aprendizaje colaborativo y el aprendizaje de múltiples perspectivas para lograr a través del pensamiento crítico, un entendimiento de fenómenos sociales. No obstante, el autor entiende que el enfoque de selección múltiple, que sirve de estructura de la gran mayoría de evaluaciones estandarizadas, no permite que los alumnos consideren múltiples perspectivas, y rara vez pueden manifestar libremente el resultado de la puesta en marcha de su pensamiento crítico.

Pérez (2013), establece que ni el desarrollo de competencias ni el de cualidades humanas cabe o es compatible con los exámenes estandarizados, pruebas objetivas o reválidas. El autor se pregunta ¿cómo esas pruebas podrán medir las emociones, las habilidades, los procesos, los comportamientos complejos, las actuaciones creativas en objetivas y económicas pruebas de papel y lápiz? E incluso, con la reválida habría que decirle adiós a posibles programas de trabajo social que se quieran distinguir del resto de los programas por aplicar pedagogías alternativas.

Para el mismo autor, es una paradoja, que aún hoy día cuando los y las estudiantes tienen fácil acceso a la ilimitada y libre exploración en Internet, cuando necesitan aprender habilidades de valoración y pensamiento crítico de orden superior, para ir formando sus criterios de discriminación, valoración, selección y propuesta de alternativas, las universidades tengan que priorizar y reducir toda su tarea, a formar estudiantes capaces de pensamiento reproductivo suficiente para pasar una reválida. Todo por el hecho de que, las cualidades de autodirección, iniciativa, creatividad, pensamiento crítico, solución de problemas y autoevaluación son difícilmente evaluables mediante instrumentos baratos y masivos de selección múltiple, como las pruebas estandarizadas. Al final de cuentas, la única forma de aprobar un examen simplificador sería asumirlo de manera robótica y olvidar que todo sistema humano es complejo, polisémico y cambiante. 
A manera de conclusión, presenté cuáles eran las presiones externas más comunes que se traen cuando se discute la posibilidad de una reválida en nuestra profesión: 1) Que seamos de las pocas profesiones que no revalidan; 2) Que existe la posibilidad que el Estado nos imponga una reválida sin nuestra consulta; 3) Que se considera que la profesión amerita tener una reválida para de esta manera ganar prestigio; 4) Que urge la necesidad de establecer un filtro de los y las egresadas de las universidades para de esta manera reducir las querellas éticas en el futuro.

Difiero de cada una. Con el primer argumento, me parece necesario enfatizar que es muy peligroso compararse con otras profesiones y concluir que somos de las pocas profesiones que no revalidan. ¿Acaso hay otra profesión que se defina por promover el cambio, el desarrollo y la cohesión social, y el fortalecimiento y la liberación de las personas? ¿Qué otra profesión tiene como principios la justicia social, los derechos humanos, la responsabilidad colectiva y el respeto a la diversidad? ¿Cuántas otras profesiones tienen mecanismos colectivos fuertes para desarrollarse como profesión? ¿Cuántos gremios profesionales tienen un proyecto profesional?

Mi militancia dentro del CPTSPR y mi apuesta a los movimientos sociales me impiden estar de acuerdo con el segundo argumento. ¿Acaso no es parte de la función del CPTSPR defender al gremio de cualquier asunto que los afecte, independientemente que provenga del Estado? ¿Ante la imposición de cualquier reglamentación nos quedaremos de brazos cruzados o nos movilizaremos como históricamente se caracterizado el CPTSPR?

$\mathrm{Si}$ en el tercer argumento, el prestigio será ofrecido por el mercado y el sector privado, personalmente a mí no me interesa dicho prestigio. Que tengamos el aval y reconocimiento de los planes médicos y agencias acreditadoras no es cónsono con mi visión de cómo la profesión debería ser reconocida. Prefiero que nos reconozca la gente, el pueblo, la sociedad. Que nuestro prestigio esté ligado a nuestras luchas por la equidad y nuestras contribuciones en la construcción de un mejor país.

Con el último argumento, de que las revalidas sirven como filtro, es muy difícil coincidir. En los casi 15 años que llevo en la profesión, no he conocido una querella ética que haya finalizado con la remoción de la licencia. En cambio, la impunidad entre los colegas es palpable en los diferentes espacios que uno comparte. Por tanto, me ha parecido que todos estos años el problema con las querellas éticas se debe a que por más esfuerzos que pongan los integrantes de la Junta Examinadora, estos son limitados por la falta de recursos, herramientas y procesos burocráticos. Asunto que una reválida no resolverá.

A modo de recapitular le apostaré en contra a que se vea la educación como un negocio y terminemos mercantilizando la profesión. Le apostaré en contra a que se establezca una reválida estilo "talla única", que tiene la intención de fracasar a los estudiantes, que homogenizará los currículos, eliminará el pensamiento crítico, que desconfía de los y las profesoras de Trabajo Social, que no es cónsona con las inteligencias múltiples, que propicia la competencia y que es incapaz de medir otras capacidades humanas más cónsonas con los valores y principios de la profesión.

En cambio le apostaré a favor a que las problemáticas que enfrenta hoy día la profesión se resuelvan de manera colectiva. No podemos seguir trayendo soluciones micro a nuestros problemas macroestructurales. Debemos comenzar a atacar el sistema que promueve las desigualdades y dejar en el pasado las concepciones que entienden que las problemáticas en nuestra profesión se deben exclusivamente a los individuos que componen nuestro gremio. Este tipo de mentalidad individualista no compagina con el Proyecto Profesional que tiene nuestra profesión, al cual soy fiel creyente. Ante los desafíos en la práctica profesional mi apuesta está en trabajarlo como un colectivo desde el proyecto profesional.

Entiendo que con respecto a la problemática de la educación del Trabajo Social en Puerto Rico, apostaría a que los principales cuerpos que conforman el colectivo profesional, reclamen y aspiren a mejorar la educación. El Trabajo Social que yo quisiera presenciar es uno en donde el gremio profesional en consultoría con las academias y a través de un proceso democrático participativo pueda crear los estándares, las competencias y las áreas de dominio que se debe enseñar en las universidades. Invito a la Asociación Nacional de Escuelas de Trabajo Social que problematice la situación de la reválida y busque mecanismos creativos, colaborativos y no punitivos para mejorar la educación del Trabajo Social en Puerto Rico.

Mi esperanza es que los cuerpos reguladores, a través de una nueva ley, delineen los procesos para que los y las profesionales cumplan con los parámetros éticos y el cumplimiento de los estándares 
de la profesión. Además, que se estudie toda la problemática antes expuesta desde su justa perspectiva estructural, y que la mirada a la precarización de la educación y de las condiciones de trabajo sean nuestro punto principal de análisis, sin que eso exima o deje impune a aquellos colegas que realmente no están cumpliendo con las regulaciones y parámetros necesarios para ser un Trabajo Social que tenga como zapata la defensa de los derechos humanos.

\section{Referencias}

Barrenechea, Ignacio. (2010). Evaluaciones estandarizadas: Seis reflexiones críticas. Archivos Analíticos de Políticas Educativas, 18, 1-27.

Díaz, Ángel. (2006). Las pruebas masivas: Análisis de sus diferencias técnicas. Revista Mexicana de Investigación Educativa, 11(29), 583-615.

Flores, Pedro. (2013). Por qué las reformas educativas necesitan de la investigación. Revista Mexicana de Investigación Educativa, 18(59), 1015-1018.

Gely, Gilda. (2007). Análisis de tasas de aprobación para certificaciones profesionales y reválidas en Puerto Rico. Investigación de la División de Investigación y Documentación sobre la Educación Superior del Consejo de Educación Superior de Puerto Rico.

Gómez, Ricardo. (2004). Calidad educativa: Más que resultados en pruebas estandarizadas. Revista Educación y Pedagogía, 16(38), 75-89.

Kearns, Laura-Lee. (2011). High-stakes standardized testing and marginalized youth: An examination of the impact on those who fail. Canadian Journal of Education, 34(2), 112-130.

López, Mabel. \& Barreto, Esterla. (2011). Desarrollo del Proyecto Profesional del Colegio de Profesionales de Trabajo Social de Puerto Rico. XXVII Jornada de Comité Mercosur de Organizaciones de Profesionales de Trabajo Social. Mendoza, Argentina.

Linn, Robert. (2001). A century of standardized testing: Controversies and pendulum swings. Educational Assessment, 7(1), 29-38.

Martínez, Felipe. (2004). ¿Aprobar o reprobar?: EI sentido de la evaluación en educación básica. Revista Mexicana de Investigación Educativa; 9(23), 817-839.

Pérez, Ángel. (2013). Revalidas, evaluación de competencias y calidad de los aprendizajes. Revista Qurriculum, 26, 11-25.

Popham, William (1999). ¿Por qué las pruebas estandarizadas no miden la calidad educativa? Educational Leadership, 56(6), 1-11.

Seda, Raquel. (2012). Legado de Carmen Rivera De Alvarado a la profesión de Trabajo Social en Puerto Rico. Voces desde el Trabajo Social. Vol. 1, 21-40

Valle, Javier. (2001). Desde la secundaria a la universidad: Tentativa de modelos para un problema poliédrico. Revista Española de
Educación Comparado. 7(19) 1-227.

Wise, Arthur. (1979). Why minimum competency testing will not improve education. Educational Leadership. May edition. 546-549. 